\title{
The Hidden Demographics Barriers of the Economic Growth: A Psychometric Approach
}

\author{
Ntogwa N. Bundala \\ Tanzania Police Force, Mara Police Regional \\ Mob:+255752 360 418/0782 338770 \\ E-mail: bundalantogwa@gmail.com
}

\begin{abstract}
This paper examined the hidden demographic barriers of economic growth. The study used a cross-sectional survey researches design. The primary data were collected by using a psychometric scale from 211 individuals who were randomly sampled from the Mwanza and Kagera regions in Tanzania. The data were linearly analysed by the weighted least squares (WLS) and Analysis weighted- automatic linear modelling (AW-ALM), and non-linearly analysed by Gaussian mixture model (GMM) and neural network analysis (NNA). The study found that the main hidden demographic barrier to economic growth is the negative subjective well-being of an individual's current age and education level. Moreover, the GMM revealed that there is no significant data or regional clusters or classes in the study population. Furthermore, NNA evidenced the most effective predictor of economic growth is age, followed by education. The study concluded that the most hidden demographic factors that hinder economic growth are negative perceptions of an individual on his/her current age and level of education, not the age maturity, and education level. Operationally or practically, the paper implicates several socio-economical policies, mostly the national aging policy (NAP), the National Education and Training policy (NETP), the National Employment Policy (NEP), and regulations /laws on national social security funds schemes at national, regional and global levels. Therefore, the paper recommended that government and other education stakeholders increase the policy commitment on the mathematics, science, and technology subjects to be compulsory for primary and secondary schools, and the extension of the retirement age from 60 years (voluntary) to 65 years (compulsory).
\end{abstract}

Keywords: Economic Growth, Hidden Demographic Barriers, Psychological Factors, Aging

JEL: J12, J16, D1, D9

\section{How to Cite:}

Bundala, N. N. (2022). The Hidden Demographics Barriers of the Economic Growth: A Psychometric Approach. International Journal of Business, Management and Economics, 3(1). 24 - 51. DOI: https://doi.org/10.47747/ijbme.v3i1.471 


\section{Introduction}

The demographic changes involve several factors such as age structure, marital status, education profiles, household size (number of family members), and others. These changes have both direct and indirect (hidden) effects on economic growth. That is, the changes can affect direct or indirect the opportunity of the individual on economic activities. For example, the changing of age structure may affect the labor market. Moreover, the increase of population also significantly affects the workforce and the education system as the government may require more costs for the construction of schools and the provision of quality health services. On the other hand, unemployment would likely increase if the population is not associated with decent works or job creation. It is a common or traditional way of studies assessing the direct impact of demographic changes such as change of age structures that directly influence the labour market. The hidden effect of the individual's demography change on economic growth is likely overlooked. Most of the studies are limited on the physical or direct effect of the demographic changes on economic growth. Therefore, this study aimed to examine the hidden or indirect effect (barrier) of the demographic factors on economic growth. Specifically, the study examined the indirect effect (barriers) of the change of age structure, marital status, education profiles, household size (number of family members), and source of income on economic growth.

\section{Empirical studies}

Empirically, the demographic factors, particularly the population aging is claimed to impact economic growth (Mester, 2017; Stephan and David, 2007; Hu, Lei, and Zhao, 2020; Song, 2013). The common empirical measures that are proxies of population change (aging) are life expectancy, mortality, morbidity, and fertility. All these variables are defining the natural variations or changes of the population's physical attributes. The study of the demographics as a part of the economics started in the early writing of Malthus (1798) on the population growth (Mester, 2017).

Recently, most of the studies concluded that demographic change (usual population change) influences the underlying growth rate of the economy, structural productivity growth, living standard, saving rate, and investments (Song, 2013; Bloom and Williamson, 1998; Yang, Zheng, and Zhao, 2021; Preston and Donaldson, n.d; Nuta and Nuta, 2020). Moreover, there is a consensus that rapid population growth in poor countries under the condition of high fertility can negatively impact economic growth (Ahlburg and Cassen, 2008; Mester, 2017; Nuta and Nuta, 2020). Mester (2017) contended that demographic factors influence the supply of labour in the sense that, when the mortality rate declines, people live longer, the supply of labour increases. Therefore, the increase in life expectancy implies that individuals will need to work longer to save more for retirement. Eventually, the population aging leads to a downward trend in the labour force participation in the aggregate.

The changing of the age distribution of workers can affect not only labour force growth and participation but also the long-run natural rate of employment (Yang, Zheng, and Zhao, 2021; Mester, 2017; Vlandas, McArthur, and Ganslmeier, 2021). Furthermore, Mester (2017) evidenced that demographic factors affect aggregate consumption, saving, and investment decisions. That is, the increase in longevity means that people will need to save more over their working life to find a longer retirement period. Therefore, the demographic factors have 
implications on the monetary policy (Mester, 2017). Several studies evidenced that changing the population from young to older affects the interest rate (Kellerman, Ferreira, and Koekemoer, 2021). Studies suggest that older people tend to hold more assets than the young and tends to be the creditors while drawing down their assets to fund their consumption during the retirements, and younger people tend to be the borrowers but face tighter credit constraints than older people because they hold fewer assets (Ogunjimi and Oladipupo, 2018; Pasichnyi and Nepytaliuk, 2021; Hippolyte, Ekrame, and Dramane, 2020; Omoruyi and Mitchel, 2021). In connection to that, older people also tend to save less than younger people because the older people once reach retirement ages, they need to draw down their retirement. This also tends to change the interest rate in the economic system. Moreover, the rising share of older people will put significant pressure on fiscal and other government policies such as social security and protection, and pension fund schemes in a country (Mester, 2017).

Mester (2017) explained the outcome of some age-related behaviour of workers in the labour market. The older workers typically have a lower unemployment rate than other age groups, and they tend to change jobs less frequently. In other words, older workers tend to stay longer in their jobs than younger workers who are likely to change jobs and employers frequently. This phenomenon, allows the older workers to gain deeper experience, which has a positive impact on productivity growth. Therefore, young people now make up a smaller share of the labour force in many countries (Mester; 2017). That is, shrinking job opportunity among the young population stress the need for flexibility not only in the labour market but in the labour force to cope with the scenario that is bound to take place once the echo generation gets old (Omoruyi and Mitchel, 2021). This is because the demographic changes affect the size of the nation's total population, working-age population, and workforce (Hippolyte, Ekrame, and Dramane, 2020; Mester, 2017; Cincotta and Engelman, 1997).

Further studies on demographic factors evidenced that demographic factors such as population change plays a role in the observed variation in the labour income share and banking services including saving (Hippolyte, Ekrame, and Dramane, 2020; Kellerman, Ferreira, and Koekemoer, 2021). The aged population has a negative impact on economic growth while the children population and labour force population stimulate the growth of the economy in the short and long-run, therefore, they support the demographic dividend hypothesis (Ogunjimi and Oladipupo, 2018). On the other hand, the cross-country study by Yang, Zheng, and Zhao (2012) evidenced the inverted U-shaped relationship between population aging and economic growth. Moreover, Fent, Mahlberg, and Prskawetz (2008) related changes in a country's age structure and its impact on economic growth and productivity. They found that there is a positive impact of the age group 50-64 years on economic growth and a negative productivity effect of the share of older workers (50+).

A recent study by Widarni and Bawono (2021) associated the demographic change in the aspect of education development as one aspect of the demographic changes. They concluded that educational development is the key to the success of increasing human capital and technological development because education plays a role in improving the quality of human resources. The increase of human resources meant to increase knowledge, mastery of the technology, innovation, and ability to develop technology to encourage technology development. 
Generally, the previous literature created critical questions such as why the aged population has a negative impact on economic growth, while the young population has a positive impact on economic growth. Why the older people tend to hold more assets than younger and older people also tend to save less compare to young people? Why do the older workers typically, have a lower unemployment rate than other age- groups, and they tend to change jobs less frequently? In other words, why the older workers tend to stay longer in their jobs than younger workers who are likely to change jobs and employers frequently? In summary, all these questions lead to one general question that "what are the psychological effects associated with the current age or/and other hidden demographic factors of the individual that influence the economic decision? To answer this general question, we need to develop a psychological scale (psychometric) of the demographic factors. Therefore, this study applied the psychological demographic scale developed by Bundala (2020) and Bundala, Ngaruko, and Lyanga (2021). This scale captures the subjective well-being of an individual's current age, level and source of income, education level, number of family members, and marital status. This scale is more important as involves a broad range of demographic factors as recommended by Le Tan and Trang (2017) and French, (2014). Therefore, this study plays an important role as it worked on the methodological gap /weakness of the previous studies.

Based on that fact, this study aimed to explore the hidden demographic factors that hinder the economic growth in Tanzania. The economic growth in Tanzania is still unpredictable and growing unevenly across regions. This phenomenon necessitates a researcher to go further beyond the determination of economic-based determinants of economic growth; hence, examined the non-economic-based determinants of economic growth. This study involved the non-economic variables that are psychological demographic factors as suggested by several studies that influence economic growth (Stevenson and Wolfer, 2008; 2013; Roka, 2020; Bundala, et al. 2021; Diener and Seligman, 2004). The study took a study sample from the Kagera and Mwanza regions which are characterised by the higher economic performance disparities in the Lake Victoria economic zone (URT, 2019a; 2019b; 2019c). The Kagera region is performing worse than the Mwanza region, while they share a lot of economic opportunities such as regional trade, economic activities in Lake Victoria such as fishing, etc. Due to this fact, it is reasonable that the economic performance disparities are due to the disparities of psychological demographic factors (non-economic variables/factors) between the two regions. Consequently, this disparity of non-economic variables between the regions leads to uneven and unpredictable growth in a country.

Therefore, this study considered the non-economic variables which are psychological (hidden) /latent demographic factors which are defined as the subjective well-being of the individual's demographic characteristics which were overlooked by the previous studies. Specifically, the study considers the five important demographic factors as suggested by Bundala (2020), Le Tan and Trang (2017), and French, (2014), which are age, marital status, number of family members(household size), education, and individual income. Thus, the study examined the economic influence of individual subjective well-being on his/her current age; level and source of income, number of family members, marital status, and education level. In fact, this study on psychological demographic factors is a vital project as it provides a model of economic growth at the micro-level (family level) of the economic production system. 


\section{Methodology}

The cross-section survey research strategy was used in this study. The primary data were randomly sampled from 211 individuals in the Mwanza and Kagera regions. The selfchecklist administered questionnaires were used to collect data as suggested to be the best tool that captures the psychological attributes of the individuals (Kothari, 2009; Kabir, 2016). The data were analysed by the weighted least squares (WLS) regression and analysis-weighted automatic linear modelling (AW-ALM) for linear modelling purposes. Moreover, the neural network analysis (NNA) and Gaussian Mixture Models (GMM) were applied for non-linear modelling purposes.

The WLS regression is an estimation technique that weights the observations proportional to the reciprocal of the error variance for that observation and so to overcome the issue of nonconstant variance (Sulaimon, 2015). For regression with cross-section data, it is usually safe to assume the errors are uncorrelated, but often their variances are not constant across individuals (Sulaimon, 2015). This problem is known as the heteroscedasticity that is unequal scatters; the usual assumption of the constant error variance is referred to as homoscedasticity. In the ordinary least squares (OLS) coefficients provide the regression equation that minimise the sum of squares errors (SSE) $=\sum e_{i}^{2}$, but in a weighted least squares (WLS) regression and the estimated equation minimised by $\sum w_{i} e_{i}^{2}$ where $w_{i}$ is a weight given to the $\mathrm{i}^{\text {th }}$ observation. Therefore, WLS regression is used in the presence of non-constant variance. If the variance of $\mathrm{i}^{\text {th }}$ observation is $\sigma_{i}^{2}$, then the weight $w_{i}=\frac{1}{\sigma_{i}^{2}}$

Therefore,

$$
\sum w_{i} e_{i}^{2}=\sum \frac{1}{\sigma_{i}^{2}} \cdot e_{i}^{2}=\sum\left(\frac{e_{i}}{\sigma_{i}}\right)^{2}
$$

Then, the entire OLS model was divided by $\sigma_{i}^{2}$ or multiplied by $w_{i}$.

That is,

$$
w_{i}\left[\ln \text { AGDP }=\beta_{0}+\sum_{i=1}^{n} \beta_{i}\left(\text { Demo }_{i}\right)\right]
$$

Where, $\beta_{0}, \beta_{\mathrm{i}}$ are constant and coefficients values of the vector of endogenous variable, Demo $_{\mathrm{i}}$

The AW-ALM has been overcome the limitations of the traditional regression model which includes the inability of automating the identifying and handling of outlying cases (Yang, 2013). Moreover, the traditional regression model is limited to the stepwise method only with no capability of conducting all possible subsets regression (Yang, 2013). The use of AWALM enriches the methodology support by offering automatic variable selection and automatic data preparation (Yang, 2013).

A Gaussian Mixture Model (GMM) is a useful tool for modelling data that comes from one of the several groups that might be different from each other, but data points within the same 
group can be well modelled by the Gaussian distribution (Reynolds, 1992). Therefore, this model is a useful tool or technique that can reveal the hidden demographic characteristics /factors across the regions. The mixture model is denoted,

$X=\left\{x_{1}, \ldots, x_{n}\right\}$ a vector of size $n$, where $x_{i} \in R^{\alpha}$

Assume that each $X_{i}$ is distributed according to a probability distribution function $f$ :

$$
f\left(x_{i} ; \theta\right)=\sum_{K=1}^{K} \pi_{k} h\left(x_{i} ; V_{k}\right)
$$

Where, $\pi_{k}$ is the mixture proportion of the group $\mathrm{k}\left(\forall k \in\{1, \ldots, K\}, 0<\pi_{k}<1\right.$, and

$$
\left.\sum_{K=1}^{K} \pi_{k}=1\right)
$$

$\theta$ is represent the model parameters. The function $h\left(.: V_{k}\right)$ is a probability distribution of dimension $\alpha$ with a parameter $V_{k}$. Therefore, for Gaussian mixture models, $h$ is a Gaussian with mean $\mu_{k}$ and variance $\sum_{k}$ and hence $V_{k}=\left(\mu_{k}, \sum_{k}\right)$.

To establish a mixture distribution of the vector variable $Z=\left\{Z_{1}, \ldots, Z_{n}\right\}$ with $Z_{i}=$ $\left\{Z_{i 1}, \ldots, Z_{i K}\right\}$ defined that;

$$
f(Z)= \begin{cases}Z_{i K}=1 & \text { If } X_{i} \text { is assigned to the } \mathrm{K}-\text { th componets } \\ Z_{i k}=0 & \text { Otherwise }\end{cases}
$$

The mixture distribution (unknown sub-population or clusters) of the population $Z$ is obtained by assigning each mixture model $X_{i}$ to component providing the highest posterior probability $\mathrm{P}_{i k}$ given by,

$$
\mathrm{P}_{i k}=\mathrm{P}_{k}\left(x_{i} ; \hat{\theta}\right)=\frac{\hat{\pi}_{k} h\left(x_{i} ; \hat{V}_{k}\right)}{\sum_{j=1}^{k} \hat{\pi}_{j} h\left(x_{i} ; \widehat{V}_{j}\right)}
$$

Now, to establish the clusters or fuzzy classification, Celeux and Govaert (1992) proposed the classification expectation-maximization (CEM) algorithm. Contrary to expectationmaximization (EM) and structural equation modelling (SEM), the CEM algorithm maximises the quantity, it is given as; 


$$
\sum_{\mathrm{i}=1}^{\mathrm{n}} \sum_{\mathrm{k}=1}^{\mathrm{k}} \mathrm{z}_{\mathrm{ik}} \log \left[\pi_{\mathrm{k}} \mathrm{h}\left(\mathrm{x}_{\mathrm{i}} ; \mathrm{V}_{\mathrm{k}}\right)\right]
$$

Since the number of components (subpopulations or classes) of the mixture model is unknown, the Bayesian Information Criterion (BIC) introduced by Schwarz(1978) as recommended for optimal selection; is penalised by entropy term (Biernacki et al. 2000). The $\mathrm{BIC}$ criterion is expressed as,

$$
\sum_{\mathrm{i}=1}^{\mathrm{n}} \sum_{\mathrm{k}=1}^{\mathrm{k}} \hat{\mathrm{Z}}_{\mathrm{ik}} \log \hat{\mathrm{P}}_{i k}
$$

To examine if there is a clear separation of the population (classes), Celeux and Soromengo (1996) proposed the Normalized Entropy Criterion that is an entropy-based criterion and measures the overlap of the mixture components (the size of the subpopulation). It is expressed as;

$$
\mathrm{NEC}_{k}=\frac{E_{k}}{L_{k}-L_{1}}
$$

Where, $E_{k}$ is the entropy of the mixture model with the $k$ components and $L_{k}$ is a complete log-likelihood (maximum likelihood estimation). This criterion is used as the diagnostic statistics for a given number of components (classes) $K^{\prime}$, if $\mathrm{NEC}_{k^{\prime}} \leq 1$, there is a clear separation of the population, i.e., the existence of the clusters in the population.

A neural network is currently the preferred tool in predicting variables (Haykin, 1998; Ripley, 1996), hence it is a time to recognise the neural network as a potential tool for data analysis (Warner and Misra, 2017). One of the advantages of the neural network over other data analysis tools is the power of the determination of the functional relationship between the dependent and independent variables (Warner and Misra, 2017). In other words, the neural network does not impose a functional relationship between the independent and dependent variables. Instead, the functional relationship is determined by data in the process of finding values for the weights (Haykin,1998; Ripley,1996). Hence, the neural network can approximate any continuous function without a pre-relationship assumption or functional form (Warner and Misra, 2017). From this fact, it is evidenced that the neural network analysis was relevant to this study. It is related to the pre-assumed functional model and this modelling doesn't require the pre assumption hypothesis of the study.

The multilayer perceptron (MLP) approach under the sigmoid function $\mathrm{S}(\mathrm{x})=1 /\left(1+\mathrm{e}^{-\mathrm{x}}\right)$ in the hidden layer and the identity function $\mathrm{C}(\mathrm{y})=\mathrm{y}$ the output layer. Where $\mathrm{x}$ is the Demo indicators which are subjective well-being of an individual on his/her current age (Age), marital status (Mari), number of family members (Nfam), and income level (Incs) and education level (Edu). On the other hand, y represents the output from the hidden layer which 
is the probability of getting the high economy (GDP Per capita =1) and getting the low economic growth (GDP Per capita $=0)$.

The internal consistency reliability was examined by using rho-A coefficients and found to range from 0.932 to 0.975 , which is within the recommended values (Hair, Risher, Sarstedt, and Ringle, 2019). This test is recommended as the best measure than the common measures such as Cronbach's alpha and composite reliability (Cronbach, 1951; Joreskog, 1971; Dijkstra and Henseler, 2015). On the other hand, the construct validity of the questionnaires (convergent and discriminant) were examined by using an average variance extracted (AVE) of the latent's construct as recommended by Hair et al, (2019). The AVE was found to range from 0.863 to 0.925 ; it is within the recommended values of at least 0.50 (Hair et al. 2019). Moreover, Henseler, Ringle, and Sarstedt (2015) proposed the heterotrait-monotrait (HTMT) ratio of the correlation to measure the discriminant validity. The HTMT ratios were found to range from 0.277 to 0.674 which are within the recommended thresholds of either 0.85 or 0.90 for dissimilar and similar items of the construct respectively (Henseler et al. 2015).

The dependent variable is economic growth which is measured by GDP per capita (regional GDP per capita in million of Tanzanian Shilling). However, the annualised income per capita will be used as a proxy for regional GDP per capita in this study. This was done by exogenous latent construct model, GPD per capita $($ AGDP) $=$ monthly income of individual $i \times 12$ (number of months in a year). The monthly income is assumed to be constant over the year, due to the nature of economic activities being similar and having almost a constant monthly return.

The endogenous variable which is a construct of psychological demographic factors (Demo) was constructed from the 5-points Likert scales, with five-dimensional observed factors which are age, marital status (Mari), income (Incs), number of family members (Nfam), and the education level (Edu). The Demo indexing model was based on the number of instrument scales or number of items or questions on each variable. The general construct model used for the psychological index is-

$$
\operatorname{Demo}_{\mathrm{i}}=\frac{\left(\sum_{i=1}^{n} \sum_{i=1}^{m} Q_{i} \cdot L S_{i}\right)}{\left(\sum_{i=1}^{n} Q_{i} \cdot L S_{\max }\right)}
$$

Where $n$ is the number of variables measured in a psychological factor; $m$ is the number of questions that measure or is a proxy for variable; $Q_{i}$ a question posed for variable $i ; L S_{i}$ the score of an individual question on the Likert Scale, and $L S_{\max }$ is the maximum score of individual questions on the Likert Scale (Bundala, 2020; Bundala, Ngaruko, and Lyanga, 2021)

\section{Results and Discussion}

\subsection{Result}

\subsection{Descriptive statistics}

The descriptive statistics of the demographic information of the respondents and variables of the study were examined to reveal the general profile of the sample population. The majority 
of the sample is in the age group of 18-40 years which composes about 74.4 percent of the total sample, and the remaining percentage is composed of the age group of 41-70 years. The gender distribution was female 35.5 percent and male about 64.5 percent. The marital statuses of the respondents are distributed as married 62.6 percent, 33.2 percent were single and the remaining percentage is included divorced and separated respondents. Moreover, the education level of the respondents distributed as primary and secondary school leavers were 55.9 percent and 35.1 percent respectively. The remaining percentage was covered by college and university levels. On the other hand, descriptive statistics for dependent and independent variables were provided (Table 1).

Table 1: The descriptive statistics for exogenous and endogenous variables

\begin{tabular}{|r|rrrrr|}
\hline Variable & Obs & Mean & Std. Dev. & Min & Max \\
\hline AGDP & 211 & 1.627217 & .7928693 & .2832 & 4.992 \\
Demo & 211 & .6264498 & .1853113 & .185 & .985 \\
Age & 211 & .6081517 & .224098 & .2 & 1 \\
Mari & 211 & .6254502 & .190341 & .2 & 1 \\
Nfam & 211 & .6140758 & .2030845 & .2 & 1 \\
\hline Incs & 211 & .6227962 & .2060357 & .2 & 1 \\
Edu & 211 & .6004265 & .2049932 & .2 & 1 \\
\hline
\end{tabular}

Source: Analysed field data (2021).

Table 1 shows the descriptive statistics of the variables used in the study. The mean values indicate that the Demo score is 0.6264 which is just above the threshold value of 0.60 , which means the population is characterised with low psychological awareness of demographic factors. Moreover, the subjective well-being of an individual on his/her current age, marital status(Mari), number of family members (Nfam), level and source of income (Incs), and the education level(Edu) is significantly low, which range between 0.6004 (Edu) and 0.6254 (Mari).

\subsection{Linear modelling of the psychological demographic factors}

In modelling of the data was transformed to natural logarithm function (ln) to meet the assumption of the statistical inference. That is the assumption of the probability distribution of the data sampled from a population such as normality and homoscedasticity. Therefore, transformations that stabilize the variance of error terms (i.e. those that address heteroscedasticity) often also help make the error terms approximately normal.

The linear model of psychological demographic factors (Demo) for economic growth was established by using the weighted least squares (WLS) regression model and analysisweighted automatic linear modelling (AW-ALM). The purpose of using these two data 
analytic methods is to re-check the empirical robustness of the post model. This re-examining enhances the conclusion on the linearity assumption of the structural model. Therefore, the WLS-stepwise regression model was run on the Demo indicators and economic growth. The Demo indicators involved in the economic growth modelling were subjective well-being of an individual on his/her current age (lnAge), marital status (lnMari), number of family members (lnNfam), level and source of income (lnIncs), and level of education (lnEdu). Moreover, the dummy variables (Mwanza and Kagera regions) were introduced to measure the geographical specificity. It is assigned 1 score for living in the Mwanza and 0 scores for living in the Kagera region. The economic growth was measured by a natural logarithm of averaged Gross domestic product per capita (lnAGDP). The WLS-stepwise regression establishes three distinctive empirical models provided in the model summary (Table 2).

Table 2: The WLS-Stepwise regression model for economic growth

\begin{tabular}{|c|c|c|c|c|c|c|c|c|c|c|}
\hline \multicolumn{11}{|c|}{ Model Summary ${ }^{\mathrm{d}, \mathrm{e}}$} \\
\hline \multirow[b]{2}{*}{$\begin{array}{l}\text { Mode } \\
1\end{array}$} & \multirow[b]{2}{*}{$\mathrm{R}$} & \multirow[b]{2}{*}{$\mathrm{R}^{2}$} & \multirow[b]{2}{*}{$\begin{array}{l}\text { Adj. } \\
\mathrm{R}^{2}\end{array}$} & \multirow[b]{2}{*}{$\begin{array}{l}\text { Std. } \\
\text { Error }\end{array}$} & \multicolumn{5}{|c|}{ Change Statistics } & \multirow[b]{2}{*}{$\begin{array}{l}\text { Durbin- } \\
\text { Watson }\end{array}$} \\
\hline & & & & & $\begin{array}{c}\mathrm{R}^{2} \\
\text { Change }\end{array}$ & $\begin{array}{c}\mathrm{F} \\
\text { Change }\end{array}$ & df1 & $\mathrm{df} 2$ & $\begin{array}{c}\text { Sig. F } \\
\text { Change }\end{array}$ & \\
\hline 1 & $.564^{\mathrm{a}}$ & .318 & .314 & $\begin{array}{c}1.307215 \\
4\end{array}$ & .318 & 97.247 & 1 & 209 & .000 & \\
\hline 2 & $.750^{\mathrm{b}}$ & .562 & .558 & $\begin{array}{c}1.049545 \\
6\end{array}$ & .245 & 116.219 & 1 & 208 & .000 & \\
\hline 3 & $.756^{\mathrm{c}}$ & .572 & .566 & $\begin{array}{c}1.040427 \\
2\end{array}$ & .010 & 4.662 & 1 & 207 & .032 & 1.608 \\
\hline
\end{tabular}

a. Predictors (Constant), ln Age

b. Predictors (Constant), ln Age, Mwanza

c. Predictors (Constant), ln Age, Mwanza, ln Edu

d. Dependent Variable ln AGDP

e. Weighted Least Squares Regression - Weighted by 1/unstandardise predicated value of $\ln A G D P$

Source: Analysed field data (2021).

Table 2 shows the model summary of the WLS-stepwise regression of Demo and economic growth. The table describes three models with their respective statistics inferences. In the first step (model 1), only the age variable (lnAge) was selected and it was significant at 0.01 , with a constant value of 0.564 and the $\mathrm{R}^{2}$ of 0.318 . In the second step (model 2), two variables were selected which are the region dummy variable (Mwanza) and the age (lnAge). In this step the significance level of $F$ changes is 0.000 , the constant value increased to 0.750 , and the $\mathrm{R}^{2}$ equals 0.562 . In the third step (model 3) more variables were included which are the age variable (lnAge), the Mwanza region dummy variable (Mwanza), and the education variable ( $\operatorname{lnEdu}$ ). The predictors' constant values increased to 0.756 , with $\mathrm{R}^{2}$ equal 0.572 . At this step, an optimal model was achieved at a maximum predictor constant of 0.756 and $\mathrm{R}^{2}$ of 
0.572. Therefore, the optimal or determinant model is determined by three variables which are region (Mwanza), age and education variables.

The unit impact of each variable was examined by the estimation of the coefficient of each unit in the model. The coefficient analysis was done from the WLS stepwise regression model, where the optimal model was achieved at step 3, in which the model has only three variables that are age, Mwanza region, and education. This optimal model has a predictor constant value of 0.756 and is determined at $0.566\left(\mathrm{R}^{2}\right)$. Therefore, a stepwise coefficient analysis was done by involving all the predictors' variables in model 3, which are age, Mwanza region, and education (Table 3).

Table 3: Unit impact (coefficients) of the WLS stepwise regression model

\begin{tabular}{|c|c|c|c|c|c|c|c|c|}
\hline \multicolumn{9}{|c|}{ Coefficients ${ }^{\mathrm{a}, \mathrm{b}}$} \\
\hline \multirow[b]{2}{*}{ Mode } & & \multicolumn{2}{|c|}{$\begin{array}{l}\text { Unstandardized } \\
\text { Coefficients }\end{array}$} & \multirow{2}{*}{$\begin{array}{c}\begin{array}{c}\text { Standardized } \\
\text { Coefficients }\end{array} \\
\text { Beta }\end{array}$} & \multirow[b]{2}{*}{$\mathrm{t}$} & \multirow[b]{2}{*}{ Sig. } & \multicolumn{2}{|c|}{$\begin{array}{l}95.0 \% \text { Confidence Interva } \\
\text { for B }\end{array}$} \\
\hline & & B & Std. Error & & & & $\begin{array}{l}\text { Lower } \\
\text { Bound }\end{array}$ & Upper Bound \\
\hline \multirow[t]{2}{*}{1} & (Constant) & .780 & .045 & & 17.148 & .000 & .690 & .870 \\
\hline & ln Age & .717 & .073 & .564 & 9.861 & .000 & .574 & .860 \\
\hline \multirow[t]{3}{*}{2} & (Constant) & .530 & .043 & & 12.249 & .000 & .445 & .615 \\
\hline & ln Age & .731 & .058 & .575 & 12.526 & .000 & .616 & .846 \\
\hline & Mwanza & .492 & .046 & .495 & 10.780 & .000 & .402 & .582 \\
\hline \multirow[t]{4}{*}{3} & (Constant) & .549 & .044 & & 12.537 & .000 & .463 & .635 \\
\hline & ln Age & .603 & .083 & .474 & 7.254 & .000 & .439 & .766 \\
\hline & Mwanza & .519 & .047 & .521 & 11.061 & .000 & .426 & 611 \\
\hline & $\ln \mathrm{Edu}$ & .187 & .087 & .144 & 2.159 & .032 & .016 & .358 \\
\hline
\end{tabular}

a. Dependent Variable $\ln$ AGDPP

b. Weighted Least Squares Regression - Weighted by1/ unstandardised predicted value of lnAGDP

Source: Analysed field data (2021).

Table 3 shows the WLS-stepwise regression model. The optimal model is model three with predictors of age, Mwanza region, and education. In step 3 (model 3) the age variable has a positive beta coefficient of 0.474 , a t-value of 7.254 , and a p-value of 0.000 , with a confidence interval of 95 percent at a range of 0.439 to 0.766 . Therefore, model 3 is optimal with economic growth determinants of age, Mwanza, and education. This is interpreted that the positive subjective well-being of an individual on age maturity (current age), and education level has a positive impact on economic growth as evidenced to have a positive beta coefficient (impact). On the other hand, the positive beta coefficient of the Mwanza dummy variable implicates that a state of living in the Mwanza region increases the economic opportunity of an individual. 
On the other hand, the AW-ALM was done for re-checking of the finding of the WLS stepwise regression model. Referring to model 3 in Table 2, all the magnitude and its directions (state of positive or negative) of the beta coefficients of both linear modelling methods are equal (Table 4).

Table 4: Analysis weighted -automatic linear modelling regression coefficients

\begin{tabular}{|c|c|c|c|c|c|c|c|}
\hline \multirow{3}{*}{ Model Term } & \multirow{3}{*}{ Coefficient $\boldsymbol{\nabla}$} & \multicolumn{3}{|c|}{$\begin{array}{l}\text { Coefficients } \\
\text { Target: In AGDP }\end{array}$} & \multirow{2}{*}{\multicolumn{2}{|c|}{$95 \%$ Confidence Interval }} & \multirow{3}{*}{ - Importance } \\
\hline & & \multirow{2}{*}{ Std.Error } & \multirow{2}{*}{$t$} & \multirow{2}{*}{ Sig. } & & & \\
\hline & & & & & Lower & Upper & \\
\hline Intercept & 1.068 & 0.047 & 22.497 & .000 & 0.974 & 1.161 & \\
\hline Region=Kagera & -0.519 & 0.047 & -11.061 & .000 & -0.611 & -0.426 & 0.681 \\
\hline Region=Mwanza & $0^{\mathrm{a}}$ & & & & & & 0.681 \\
\hline InAge_transformed & 0.603 & 0.083 & 7.254 & .000 & 0.439 & 0.766 & 0.293 \\
\hline InEdu_transformed & 0.187 & 0.087 & 2.159 & .032 & 0.016 & 0.358 & 0.026 \\
\hline \multicolumn{8}{|c|}{ aThis coefficient is set to zero because it is redundant. } \\
\hline
\end{tabular}

Source: Analysed field data (2021).

Table 4 shows the analysis weighted-automatic linear modelling (AW-ALM) regression model. The automatic linear modelling was weighted by a standard deviation. The optimal model was established by age, education, and region dummy variables that coincided with the WLS modelling approach. Therefore, psychological demographic determinants of economic growth are age, Mwanza region, and education which were analytically confirmed.

\section{3: Non-Linear modelling of psychological demographic factors}

The non-linear modelling was done by using the Gaussian Mixture models (GMM) and neural network analysis (NNA). The application of GMM aimed to reveal the hidden heterogeneity behaviour of the population on the psychological demographic factors. The selection of the 
mixture models was done by using the BIC condition. The study evidenced the sample population can be clustered into two classes or subpopulations. That is, according to the BIC condition, the best mixture model is the $\mathrm{V}$ (Variable variance) with 2 component(s) (Table 5).

Table 5: The evolution of the BIC for Demo construct

\begin{tabular}{lrrrr}
\hline \multicolumn{1}{c}{ Model/Number of classes } & \multicolumn{1}{c}{2} & \multicolumn{1}{c}{3} & \multicolumn{1}{l}{5} \\
\hline V(Variable variance) & $\mathbf{1 0 4 . 8 4 6 8}$ & 101.495 & 90.476 & 74.352 \\
E(Variable Mean) & 92.176 & 84.57754 & 89.379 & 78.675 \\
\hline
\end{tabular}

Source: Analysed field data (2021).

Table 5 shows that the best mixture model under the BIC condition is determined by variances of the variables, at a BIC value of 104.8468 which is the highest value. The graphical presentation of the mixture models was presented (Figure 1).

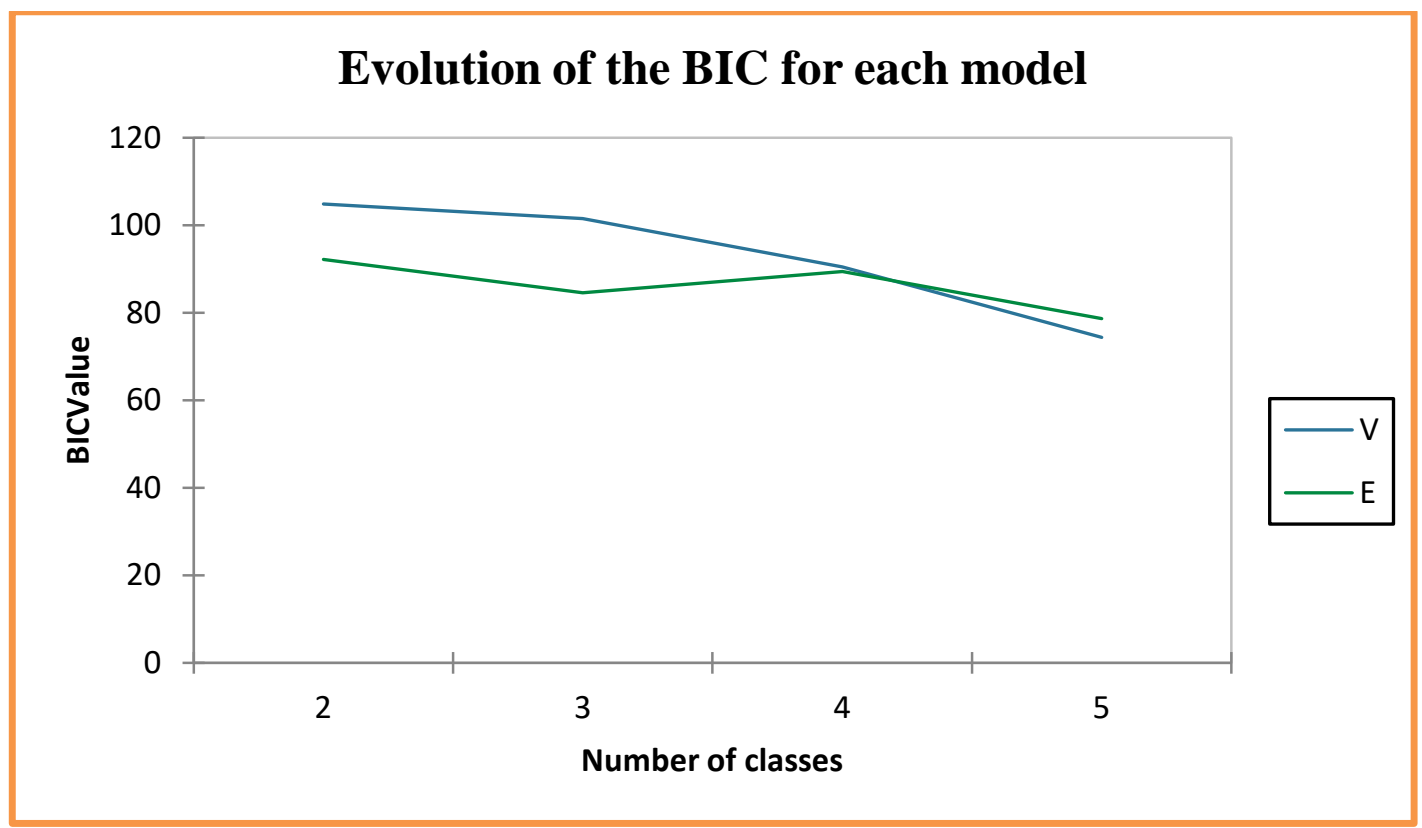

Figure 1: The graphic presentation of the mixture model under the BIC condition Source: Analysed field Data (2021).

Figure 1 shows the best mixture model is the $\mathrm{V}$ (Variable variance) with 2 component(s). The EM algorithm converged in 331 iterations. The optimal number of classes occurs at the minimum choice. The algorithm should be run with a minimal number of classes fewer than 2. 
The size (proportion) of the classes or clusters was established as 0.843 for class 1 and 0.157 for class 2. This means that class 1 is composed of 84.3 percent of the population sampled from the Mwanza and Kagera regions. The rest percentage (15.7\%) as belonging to class 2 (Table 6).

Table 6: The classes size, means, and variances values of the Demo

\begin{tabular}{lcc}
\hline Class & 1 & 2 \\
\hline Proportions & 0.843 & 0.157 \\
\hline Mean (Demo) & 0.577 & 0.889 \\
\hline Variance (Demo) & 0.025 & 0.003 \\
\hline
\end{tabular}

Source: Analysed field data (2021)

Table 6 shows the classes' size or proportion of the sample population that is determined by the two mixture models. The consequential question is what are the features that distinguish the two classes? The post-analysis reveals that class 1 has a Demo mean value of 0.577 , and class 2 has a Demo mean value of 0.889 . From this empirical fact, it is obvious that class 1 was characterised by the low psychological demographic factors (Demo), and class 2 was characterised by the respondents with high psychological demographic factors (Table 6).

Moreover, class 1 has a Demo variance of 0.025 and class 2 has a Demo variance of 0.003 . In comparison, the individuals' psychological demographic factors in class 1 vary greatly than in class 2. Post-analysis also reveals that the class separation size of 0.843 which is equal to 172 respondents in class 1 and 0.157 which is equal to 39 in class 2 (Table 6) indicates that there are no regional-based clusters since the sample population composes 211 individuals, 100 from Mwanza and 111 from Kagera region(Table 6).

Table 6: Selection criterion for the selected model and sum of weights

\begin{tabular}{|c|c|c|c|c|c|c|}
\hline $\mathrm{BIC}$ & AIC & ICL & Log-likelihood & NEC & Entropy & $\mathrm{DF}$ \\
\hline 104.847 & 121.606 & 46.263 & 65.803 & 3.251 & 29.292 & 5.000 \\
\hline \multicolumn{7}{|c|}{ Results by class: } \\
\hline Class & 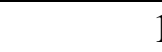 & 2 & & & & \\
\hline Objects & 17 & 39 & & & & \\
\hline Sum of weights & 17 & 39 & & & & \\
\hline
\end{tabular}

Source: Analysed field data (2021)

Table 6 describes the class objects, a sum of weights, and the selection criteria for the selected mixture models; the BIC condition was used to select the mixture model. Although at this value (104.847) of BIC, 2 mixture models were described; the NEC criterion is greater than 1 which indicates that there is no clustering structure in the data. The mixture models are classified by MAP of the Demo (Figure 2). 


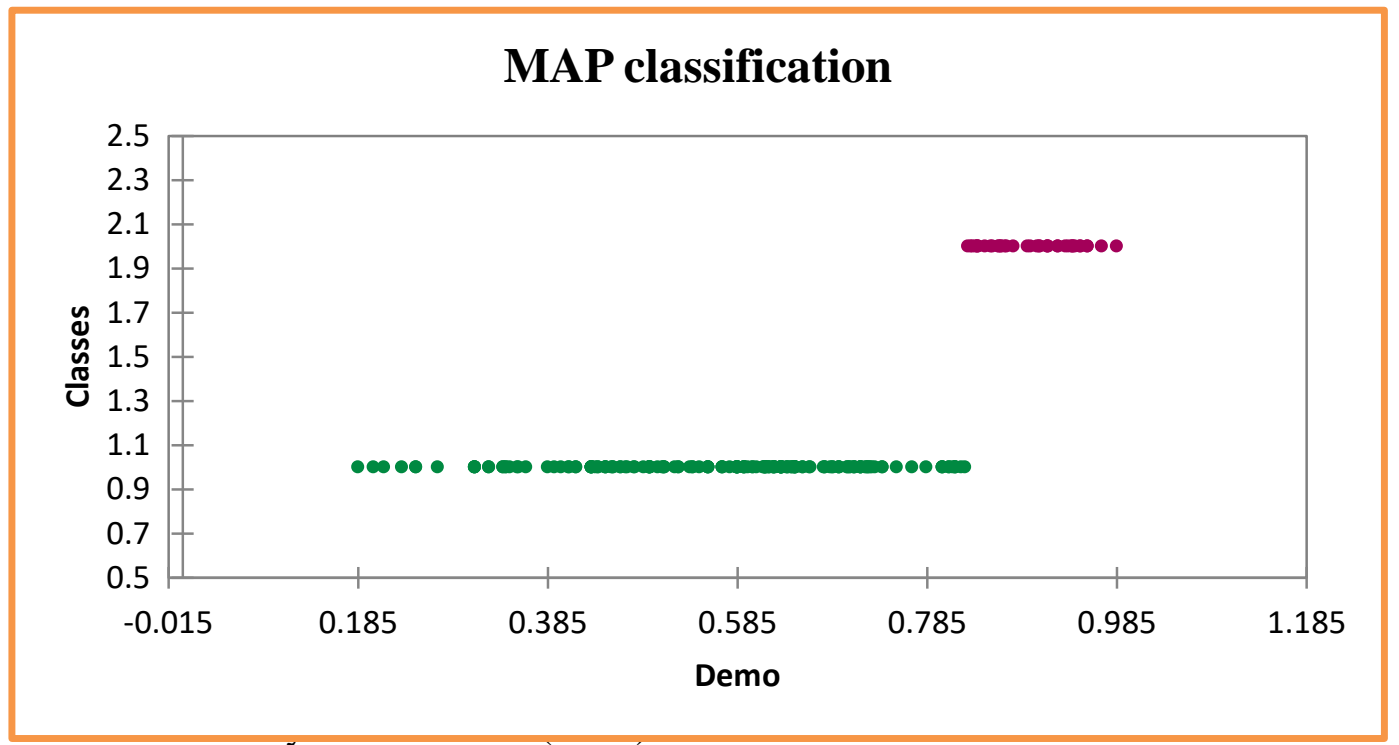

Figure 2 shows the MAP classification of the Demo in the Mwanza and Kagera regions. The largest class is class 1 which is denoted by a horizontal green line (bar), which starts just below 0.185 Demo score to just above 0.785 Demo score. On the other hand, class 2 is the smallest class which is denoted by a pink or dark-red colour line (bar) in a graph. Its Demo score starts from just below 0.785 Demo score to just above 0.985 Demo score. Therefore, the population of the Mwanza and Kagera regions has almost equally behaved in psychological demographic characteristics, as it is evidenced that about 84.3 percent of the sample population belongs to class 1 . The fitted mixture models of Demo were provided to indicate the empirical distributions of the classes (Figure 3).

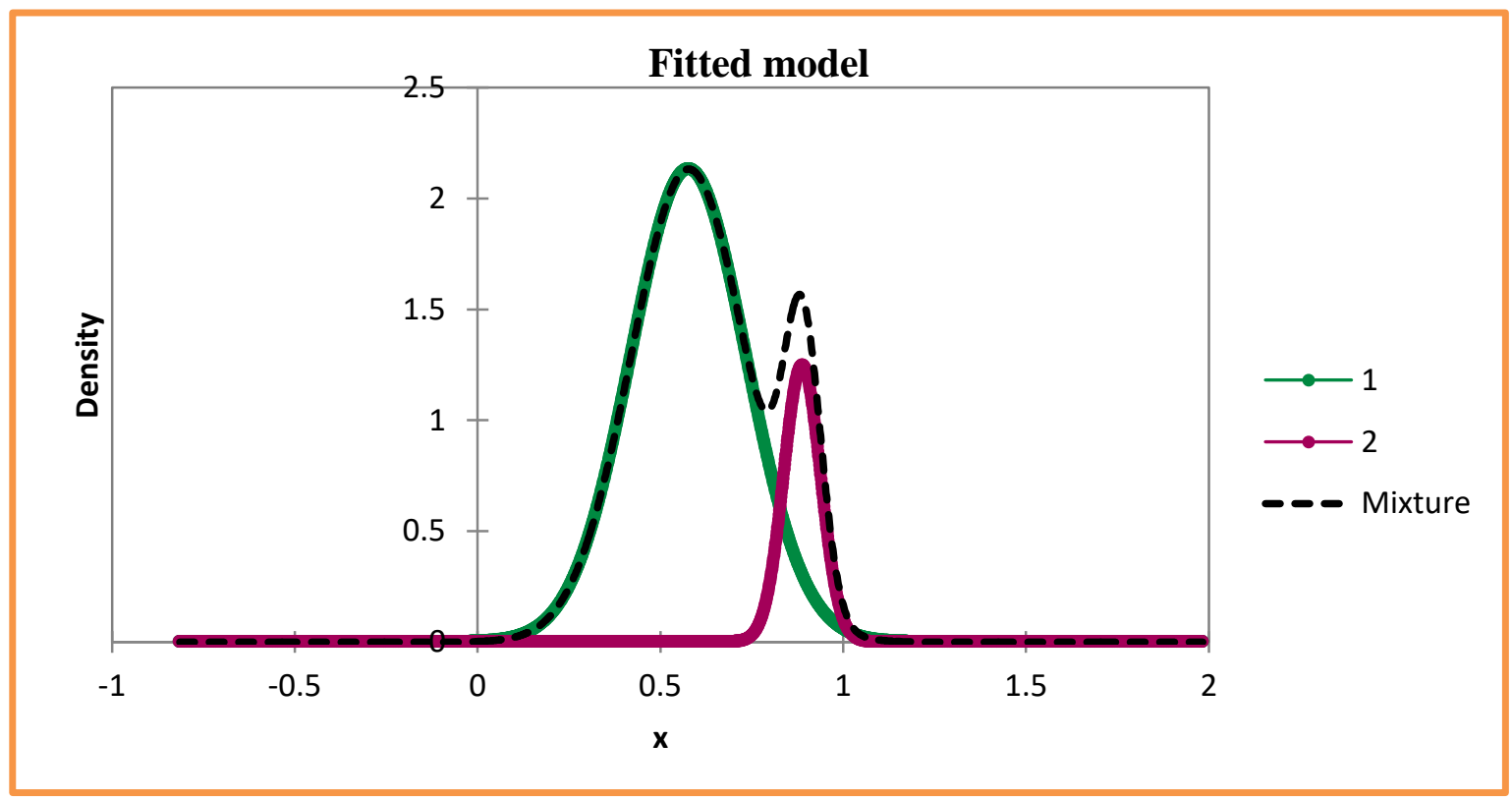

Figure 3: The fitted models of the mixture models (class 1 and class 2 models) 
Source: Analysed data (2021).

Figure 3 shows the mixture models of the Demo in the Mwanza and Kagera regions. This figure describes the probability distribution of the MAP classification. The highest distribution with green colour is for class 1 that indicates that data were normally distributed. Moreover, the diagnostic plot of the mixture models was provided by the cumulative distribution function (Figure 4).

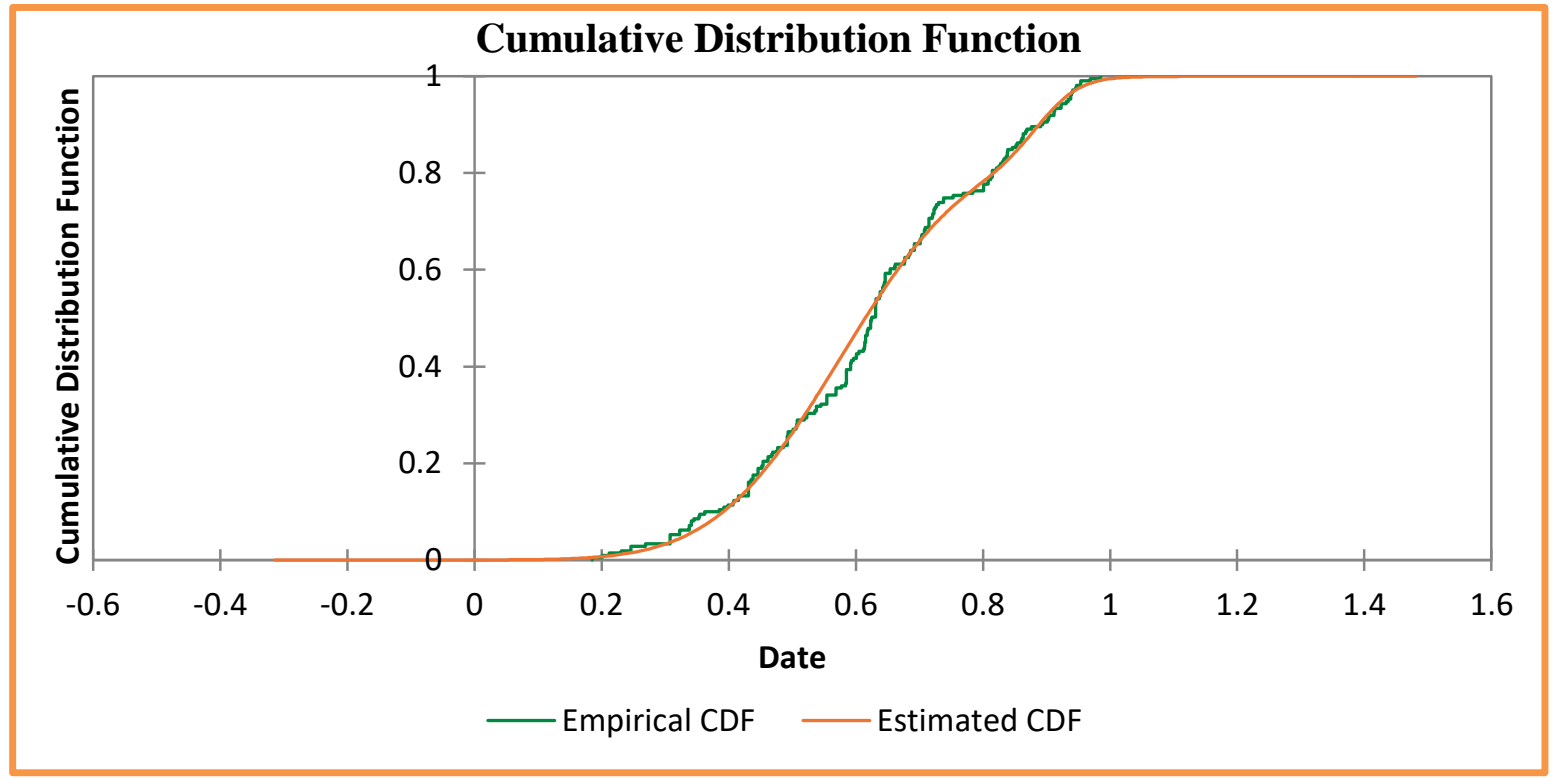

Figure 4 shows the overlaid empirical CDF and estimated CDF. The estimated CDF indicates the fits of the data on the theoretical assumption of data distribution. On the other hand, the empirical CDF indicates the fits of the sampled data from a study sample. The significant (close) overlay of both empirical and estimated CDF indicates that the data fit the theoretical assumption of the study. Therefore, as this figure indicates the close overlay of both empirical and estimated $\mathrm{CDF}$, the data of this study are over fits the theoretical assumption that they were normally distributed.

Furthermore, the non-linear modelling of psychological demographic Factors (Demo) for economic growth was established by using the neural network analysis. The sigmoid activation function was applied in the hidden layer and the identity function was applied in the output model. The model summary was provided (Table 7) 
Table 7: The neural network model summary for Demo indicators

\begin{tabular}{llc}
\hline Model Summary & & \\
\hline Training & Sum of Squares Error & 38.165 \\
& Relative Error & .502 \\
\cline { 2 - 3 } & Stopping Rule Used & 1 consecutive step(s) with no decrease in error \\
\cline { 2 - 3 } & Training Time & 00000.03 \\
\hline Testing & Sum of Squares Error & 9.566 \\
\cline { 2 - 3 } & Relative Error & .444 \\
\hline Dependent Variable ln AGDP & \\
\hline
\end{tabular}

Source: Analysed field data (2021).

Table 7 shows the summary of neural network modelling of the Demo indicators and economic growth. In the training sample, the model has a sum of squares error (SSE) of 38.165 and a relative error of 0.502 . The stopping rule used is 1 consecutive step(s) with no decrease in error, which means that errors are computed on the testing sample. The training time was 00000.03 minutes. The stopping rule is the rule that determines when to stop training in the neural analysis, this rule, means that the training process will stop if there is no decrease in estimation error in the model. In the testing sample, the SSE of the model is 9.566 which is considered minimal, indicating the model has a high predictive ability as its relative error in the testing sample was 0.444 .

The network architecture of the neural network model was used to specify the structure of the connectionism (network) of neurons (perceptrons). The architecture of the model was established to reveal the relevance of each variable. The architecture has three parts/layers, input layer, hidden layer, and output layers (Figure 5). The input layer is the first layer that contains the predictors. The hidden layer contains unobservable nodes or units where the computational or mathematical function is done by application of activation functions and the output layer which contains the responses. 


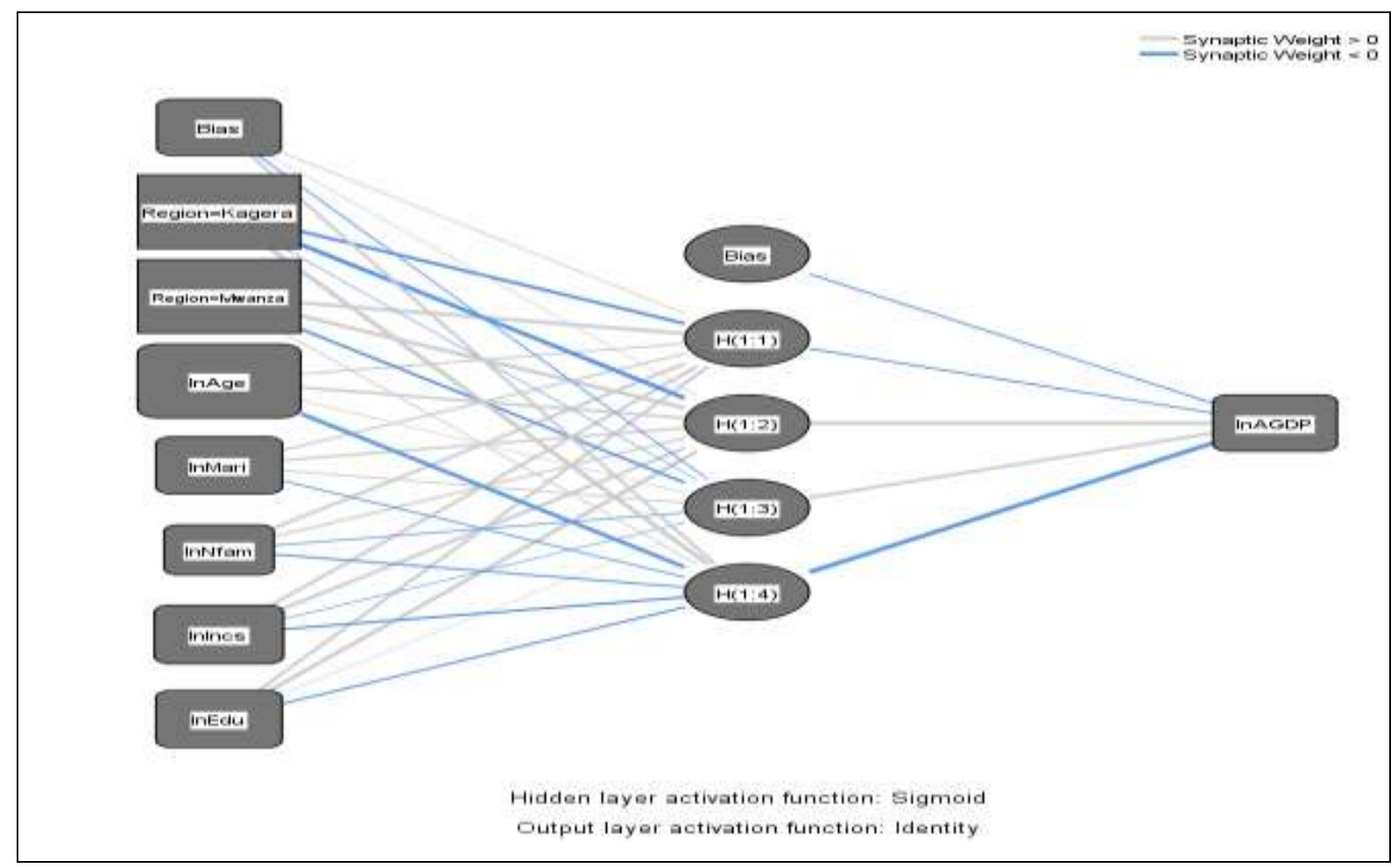

Figure 5: The Feed-forward network architecture with one hidden layer

Source: Analysed field data (2021).

Figure 5 shows the feed-forward network architecture with one hidden layer. It represents the non-linear structural model of Demo indicators and economic growth under the sigmoid activation function on the hidden layer and identity function on the output layer. In the hidden layer node 4 ( $\mathrm{H}(1: 4))$, the combination of age (most important and positive), Kagera region (most important and positive), marital status, number of family members, income, and education (less important but negative) have an important positive impact on economic growth. The positive subjective well-being of an individual on age has an important and positive impact on economic growth. On the other hand, the hidden layer nodes 2 and 3 (H $(1: 2), H(1: 3))$ their predictors' combination has important negative effects on economic growth, and in node $1(\mathrm{H}(1: 1))$ the combination of the predictors has less important positive effects (insignificant impacts). Therefore, the hidden layer node 4 (H (1:4) is the optimal model.

On the other hand, the neural network analysis provides the sensitivity of the predictors by examining the importance and its normalized values. The simple bar chart presents the importance of the predictors by placing the most important (sensitive) predictor on economic growth on the top, and the least important predictor placed at the bottom (Figure 6). 


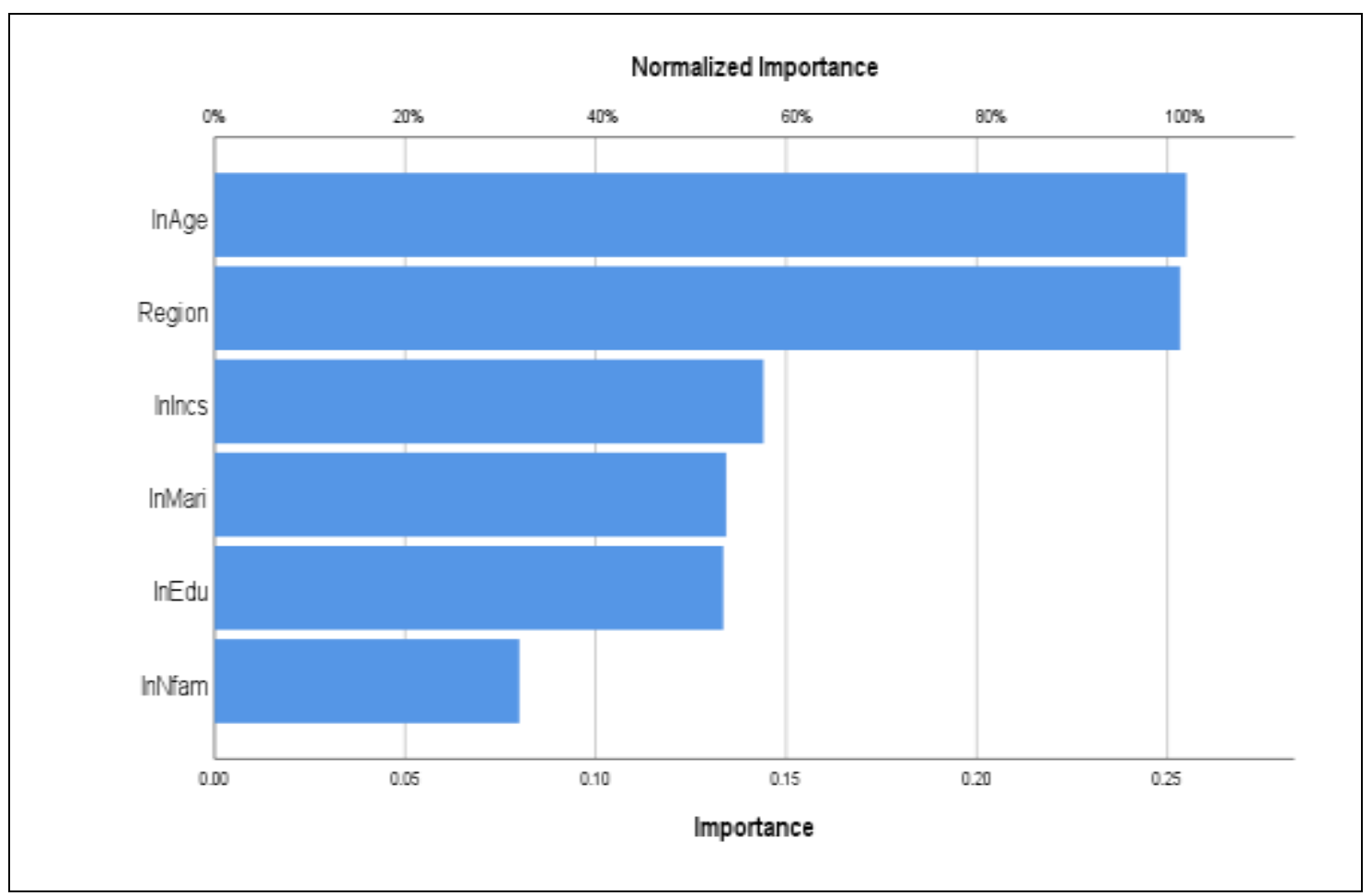

Source: Analyzed field data (2021).

Figure 6: The sensitivity analysis of the predictors in the neural network

Figure 6 shows the simple bar chart for the normalized importance of the predictors of the neural network model. The most two important predictors are the age variable (lnAge) and region dummy variables (Mwanza and Kagera regions), and the least important predictor is the number of family members (lnNfam).

\subsection{Discussion of findings}

The study aimed to examine the hidden demographic barriers of economic growth in Tanzania. The hidden demographic barriers are defined as the subjective well-being of the individual's current age, source and level of income, number of family members, marital status, and education level. Empirically, this study confirmed that only the subjective wellbeing of the individual's current age and education level significantly influences the economic growth in Tanzania. Several studies support this finding. Most of the recent studies contended the population that is capacitated in educations, particularly, secondary and tertiary education is advantaged to explore the new knowledge, skills, technology, and innovation, highly labour market efficiency, and entrepreneurs; therefore, they enhance the economic growth (Maneejuk and Yamaka, 2021; Marquez-Ramos and Mourelle, 2019; Gant, 2017; Aghion, Boustan, Hoxby and Vandenbussche, 2009; York, n.d). Specifically, basic education (both primary and secondary levels) is claimed to suffice for the simple production of goods and services and allows workers to use the available technology in the workplace. Moreover, 
higher education is equipping the graduate with the potential capabilities to invest in new technology and help transform the country into a knowledge-based economy (Maneejuk and Yamaka, 2021). On the other hand, the migration of workers with higher education has a significant impact on strengthening the competitiveness and economic development of the country (Oliinyk, Bilan, Mishchuk, Akimov, Vasa, 2021).

The advantages of education are not limited only to economic issues, but it covers a broad range of life experiences of an individual. According to Ozturk (2001), education enriches people's understanding of themselves and the world. It improves the quality of their lives and leads to broad social benefits to individuals and society. In addition, education raises people's productivity and creativity and promotes entrepreneurship, and technological advances (Ozturk, 2001; Maneejuk and Yamaka, 2021; Marquez-Ramos and Mourelle, 2019). Also, better education might lead an individual to a better decision about health, marriage, and parenting style, therefore, education makes individuals more goal-oriented and less likely to engage in risky behaviour (Goczek, Witkowska, and Witkowski, 2021). Relying on these empirical facts, it is oblivious that education does not directly impact economic growth; it impacts through mediation factors such a through the labour market, social, cultural, and political determination/ awareness of an individual. Therefore, there is a nonlinear relationship between education and economic growth (Maneejuk and Yamaka, 2021; Grant, 2017; Marquez-Ramos and Mourelle, 2019). Some empirical studies evidence that education plays the dual role of being a determining factor of economic growth as well as the force driving its nonlinear behaviour (Marquez-Ramos and Mourelle, 2019; Odit, Dookhan, and Fauzel, 2010; Widarni and Bawono, 2021). Moreover, the direction of the causality is from education to economic growth and government expenditure to education (Krokeyi and Niyekpemi, 2021; Marquez-Ramos and Mourelle, 2019; Cooray, 2009). It means the improvement of education is the preliminary requirement for economic growth. Therefore, this study confirms that an individual who perceives his/her education level as adequate and the most important in his/her life has a higher opportunity for economic growth, and it is vice versa.

On the other hand, this study empirically evidenced that the subjective well-being of an individual's current age has a positive impact on economic growth. The finding of this study is supported by several studies. The issues of aging as economic impact factors have been addressed by many researchers. Most studies on the economic and aging problem consensuses that an individual's physical capacity, preference, and needs are changing in line with age advancement. Hence, inequality of age structure is believed to affect the country's productivity level (Nagarajan, Teixeira and Silva, 2016; Bloom, Canning, and Fink, 2010; Wijaya, Tasente, Darma and Kasuma, 2021; Huang, Lin, and Lee, 2019). Bloom, Canning, and Fink $(2010,2008)$ detailed this age-based change of an individual. They explained that behaviour changes induced by changing expectations about the life cycle, for example, individuals' expectations of living longer than the previous generation, may induce them to remain in a work for longer and begin to draw down savings at a later age. In other words, behavioural responses to population aging can occur in the form of higher savings for retirement and greater labour force participation. One of the policy implications of the aging problem is to change the retirement incentives, so that people can fulfill their expressed desire to work longer in response to the expectation of greater longevity (Bloom et al., 2010; 
Bundala, 2017). In a specific way, empirical studies confirmed that population at the age of 60 years and above decreases the economic growth rate of GDP per capita (Maestas, Mullen and Powell, 2016; Pham and Vo, 2019; Madsen, Daumerie and Hardee, 2010; Bloom et al., 2010; 2008; Alexia, Tomas, Sanderson and Sergei, 2004). Therefore, aging is negatively impacting economic growth (Bundala, 2017; Rahman, Ismail, and Ridzuan, 2020; Huang et al., 2019; Vlandas et al., 2021). Therefore, these empirical supports on this finding, it is empirically justified that an individual who thinks or perceives that his/her are current age gives more opportunity to invest in future, he/she is likely to perfume well in economic growth.

\section{Conclusion}

Based on the fact that the education and age subjective well-being of an individual has a significant positive impact on the economic growth; therefore, it is generally accepted that the most hidden demographic factors that hinder the economic growth are the negative perception of an individual on his/her current age and level of education. In other words, what are matters in economic growth is the subjective well-being of an individual's ages and education level. This is why are called the hidden (psychological) demographic factors! From this fact, an individual, a secondary school leaver who is happy (satisfactory) with his/her level of education (positive subjective well-being) has a positive significant impact on economic growth, and it is vice versa. This demonstrative phenomenon can be interpreted wrongly if only the physical features (age in years and education levels) were used to judge their income differences. One can conclude that higher education is useless or age maturity is nothing in fostering economic growth.

This study implicated several policies in Tanzania. The first national policy implicated by this study is the National Ageing Policy (NAP). The policy contended that older people who are at least 60 years old are among the poorest in society. Besides being skilled, knowledgeable, and experienced as a farmer, fishermen, and retired public servants, the majority of them go into retirement ill-prepared (URT, 2003). Therefore, the NAP set its economic-based objectives to allocate resources for older people's income generation activities and their welfare; and to initiate and sustain programs that provide older people with an opportunity to participate in economic development initiatives. Therefore, older people individually or in the group will be sensitised and mobilised in establishing income-generating activities, and the Local Government Authorities and Voluntary Agencies to incorporate older people's groups in income-generating activities (URT, 2003). Moreover, in line with the National Health Policy (NHP), older people were ensured to receive basic health services (URT, 2003; 2017). Concerning these policy objectives, this study found that people at the age of 60 years and above are characterised by the low motivation of economic activities, most of them consider themselves (perceived themselves) that they are less energetic and need more assistance from the government and community. They are psychologically affected by pre-retirement income or wage syndrome in accordance with the theory of permanent income (income generated from their wage employment or reliable source of income, e.g., farming and fishing). The post-retirement income which includes retirement benefits and other incomes provided by the national social security funds such as the National Social Security Fund (NSSF), Public 
Service Pension Fund (PSPF), Governmental Employees Provident Fund (GEPF), Local Authorities Pensions Fund (LAPF) and Parastatal Pension Fund (PPF) after retirement not easily managed and handled because they do not follow a wage system. Therefore, most of this income perishes due to improper use by retirees or other related beneficiaries. Notably, this study evidenced that older people prefer to save rather than invest.

In addition, the economic opportunity of the elder people is limited as they are excluded in the labour market policy such as the National Employment Policy (URT, 2008). In general, older people or retired people suffer more from age-psychological-related problems rather than income-related problems. The NAP overlooked the psychological effects associate the age advancing. Therefore, it will be difficult to achieve the policy objective if the psychological aspect individual's age will not be addressed. Moreover, the policy declares that the reason for older people to be among the poorest in society is due to fact that they are ill-prepared for their retirement. What are effective preparatory policy objectives? The NAP provides the preparatory policy objectives that the government in collaboration with stakeholders will sensitise the society and youth in particular on the stages and various old age-related problems. Moreover, the government in collaboration with stakeholders will educate and establish capacity-building programmes for the youth to prepare them for responsible old age and aging to be taught as a topic in the civics subject (URT, 2003). Therefore, this study implicates the way in how the government in collaboration with stakeholders sensitizes the society and youth on the retirement plans, ways of educating them, and establishing capacitybuilding programmes for the youth to prepare them for retirement. These sensitized and capacity-building programs should be involved the psychological demographic factors, particularly the subjective well-being of an individual at his/her current age, as this study found to have a significant influence on the post-retirement income.

Furthermore, this study recommended that to enhance the economic contributions of the elder people, the government should open more economic opportunities for them. And this will be stipulated in the national employment policy as now they are excluded. The role of elder people is shifted from economic role to social and political role where are seemed to be required. On the other hand, the retirement age should be restructured from 60 years old as voluntary retirement and 65 years old for compulsory retirements as empirical evidence shows the most people have a natural death at more than the theoretical life expectancy of 58.2 years and 60 years for men and women respectively.

The finding of this study also posed an implication on the National Education and Training Policy (NETP), and Information and Communication Technology (ICT) Policy for basic education in Tanzania. This study evidenced that education particularly quality higher education has a significant positive impact on economic growth. In line with the NETP, a country needs a quality education that will foster economic growth through innovation and technological advancement. One of the policy requirements is to increase the adequate number of people who are educated in science and technology to meet the national development needs. That is, the government should improve the education and training infrastructure of the Mathematics, Science, and Technology (MST) subjects at all levels of education and training (URT, 2014). Consequently, the policy emphasised the use of science and technology in the provision of education and training at all levels. Adversely, it is evidenced that the policy pays little consideration to the MST subjects as allows the form 
three students to opt either to continue to study MST or not. This is not only a major policy weakness but also a "diverging" development mission/plan that cannot achieve the vision target that is the economic growth in Tanzania. This is because a country is technologically incapacity which is adverse to economic growth. It is estimated that about 30- 35 percents of the students enter form three opt for MST subjects (URT, 2014). Only mathematics and biology are compulsory science subjects that are lent by students from form one to four, with unsatisfactory performance (URT, 2014). Moreover, it is evidenced that the knowledge and skill of the school/college leavers are lower than that expected (URT, 2014).

In addition, the supplemental policy that enhances the use of ICT in basic education is the Information and Communication Technology (ICT) Policy. This policy is expected to increase the number and quality of teachers, through improved pre-service and in-service training and better provision of teaching and learning materials (URT, 2007). The use of ICT is also expected to enhance the acquisition and use of knowledge and skills for all learners, including those with special needs. ICT use will improve the efficiency and effectiveness of the management and administration of education, at all levels (URT, 2007). One of the hidden psychological barriers that evidenced/anticipated is the lack of awareness among decisionmakers, development partners, and private sector investors on the importance of ICT for education as well as local and national development (URT, 2007). Therefore, this study recommends to the government and other education stakeholders to increase the policy commitment on the mathematics, science, and technology subjects to be compulsory for primary and secondary schools. Moreover, the implementation of the ICT policy should be preceded by a formal awareness campaign or programmes on the decision-makers, development partners, and private sectors to understand the importance of ICT for education and economic growth.

\section{References}

Aghion, P., Boustan, L., Hoxby, C. and Vandenbussche, J.(2009). The Causal Impact of education of economic growth; evidence from U.S. Harvard University and CEPR.

Ahlburg, D. and Cassen, R.(2008). Population and development. In ; Dutt, A.K. and Ros, J. (eds) pp.316-327. International handbook of development economics. Choltenham, Edward Elgar, UK.

Alexia, P., Tomas, K., Sanderson, W.C. and Sergei, S.(2004). The effect of age structure on economic growth; an application of probabilistic forecasting to India. Vienna Institute of Demography working paper no. 03/2004. Austrian Academic science(OAW), Vienna institute of Demography (VID), Vienna.

Biernacki.C., Celeux G. and Govaert. G. (2000). Assessing a mixture model for clustering with

Bloom, D.E and Williamson, J.G.(1998). Demographic transitions and economic miracles in emerging Asia. The World Bank Economc Review, 12(3), 419-455. 
Bloom, D.E., Canning, D. and Fink, G.(2008). Population aging and economic growth. Commission on Growth and development, working paper No. 32. The World Bank, 1818, H street NW, Washington, DC 20433, USA.

Bloom, D.E., Canning, D. and Fink, G.(2010). Implications of population aging for economic growth. Oxford Review of Economic Policy, 26(4), 583-612.

Bundala, N.N. (2017). The demographic and aging intensity and its economic Threats: Chinese Experiences. International Journal of Advanced Research and Publication, 1(3), 92-98.

Bundala, N.N.(2020). The Latent Content Model of Economic Growth. International Journal of Economics, 5(1), 13-52.

Bundala, N.N., Ngaruko, D.D.P. Lyanga, T.M. (2021). Is Living in Mwanza Region More Economically Better and Happier than Living in Kagera Region? Finite Mixture (FIMIX) Approach. Asian Journal of Economics, Business, and Accounting, 21(6): 12-26. doi: 10.9734/AJEBA/2021/v21i630387

Celeux, G. and Govaert, G. (1992). A classification EM algorithm for clustering and two stochastic versions. Computational Statistics \& Data Analysis, 14, 315-332.

Celeux, G. and Soromenho, G. (1996). An entropy criterion for assessing the number of clusters in a mixture model. Journal of Classification, 13, 195-212.

Cincotta, R.P. and Engelman, R.(1997). Economic and Rapid changes: the influence of population growth. Occasional paper, Population Action International.

Cooray, A.(2009). The Role of Education in Economic Growth. $38^{\text {th }}$ Australian Conference of Economists, Adelaide, 2009, SSRN Electronic Journal.

Cronbach, L. J. (1951). Coefficient Alpha and the Internal Structure of Tests. Psychometrika, $16,297-334$.

Diener, Ed. and Seligman, M.E.P. (2004). Beyond Money toward an Economy of WellBeing. Journal of Psychological Science in the Public Interest, 5(1), 1-31.

Dijkstra, T. K., and Henseler, J. (2015). Consistent and Asymptotically Normal PLS Estimators for Linear Structural Equations. Computational Statistics \& Data Analysis,81(1), 10-23.

Fent, T., Mahlberg, B. and Prskawetz, A. (2008). Demographic changes and economic growth. In: Kohlbacher, F., Herstatt, C. (eds), The silver market phenomenon. Springer, Berlin, Heidelberg. doi: org/10.1007/978-3-540-75331-5_1

French, C. (2014). Why Demographic Data Matters. Community Planning New Hampshire. Information Brief No. 1, November 2014.

Goczek, L., Witkowska, E. and Witkowski, B.(2021). How does education quality affect economic growth? Sustainability, 13, 6437, doi: org/10.3390/su13116437

Gant, C. (2017). The contribution of education to economic growth. institute of development studies, knowledge, evidence and learning for development, K4D, help desk report, UK. 
Hair, J.F., Risher, J.J., Sarstedt, M. and Ringle, C.M. (2019). When to Use and How to Report the Results of PLS-SEM. European Business Review, 31(1), 2-24. doi 10.1108/EBR-11- 2018-0203

Haykin, S. (1998). Neural Networks A Comprehensive Foundation. Prentice-Hall, Englewood Cliffs.

Henseler, J., Ringle, C.M. and Sarstedt, M. (2015). A New Criterion for Assessing Discriminant Validity in Variance-Based Structural Equation Modelling, Journal of the Academy of Marketing Science, 43(1), 115-135.

Hippolyte, D., Ekrame, B. and Dramane, C.(2020). Demographic changes and the labour income share. 2020. Halshs-0227876v2. Working paper no. 2019-46.

Hu, Q., Lei, X . and Zhao, B. (2020). Demographic changes and economic growth; impacts and mechanism. China Economic Journal. doi: 10.1080/17538963.2020.1865647

Huang, W.H., Lin, Y.J. and Lee, H.F. (2019). Impact of population and workforce aging on Economic growth; a case study of Taiwan. Sustainability,11, 6301, doi:10.3390/su1122 6301 Intelligence, 22, 719-725.

Jöreskog, K.G.(1971). Simultaneous Factor Analysis in Several Populations. Psychometrika, 36(4), 409-426.

Kabir, S.M.S. (2016). Basic Guidelines for Research An Introductory Approach for All Disciplines. Book Zone Publication, ISBN 978-984-33-9565-8, Chittagong-4203, Bangladesh.

Kellerman, D., Ferreira, S. and Koekemoer, Z.D. (2021). The impact of demographic on investment. Spring/summer, 57, 91-105.

Kothari, C.R. (2009). Research Methodology Methods and Techniques, (2 ${ }^{\text {nd }}$ Ed.) New Age International Publishers. New Delhi.

Krokeyi, W.S., and Niyekpemi, B.O. (2021). Human capital and economic growth nexus in Nigeria. Journal of Global economics and Business, 2(6), 36-49.

Le Tan, T. and Trang, D.T.D. (2017). The Effects of Demographic Variables on Knowledge Sharing Behaviour. Jurnal Ekonomi Bisnis , 22(2), 107-116.

Madsen, E.L., Daumerie,B and Hardee, K. (2010). The effects of Age structure on Development. Policy and Issue brief, pp.1-4. Population Action International, Health Families, Health planets, $130019^{\text {th }}$ Street, NW, $2^{\text {nd }}$ Floor, Washington, DC 20036, USA.

Maestas, N., Mullen, K.J. and Powell, D.(2016). The effect of population aging on economic growth, the labour force, and productivity. RAND Corporation, Santa, Monica, Calif.

Malthus, T. R. (1798), An Essay on the Principle of Population as It Affects the Future Improvement of Society, with Remarks on the Speculations of Mr. Godwin, M. Condorcet, and Other Writers, London, J. Johnson.

Maneejuk, P. and Yamaka, W.(2021). The impact of higher education on economic growth in ASEAN-5 countries. Sustainability, 13, 520. doi: org/10.3390/su13020520. 
Marquez-Ramos, L. and Mourelle, E. (2019). Education and economic growth; an empirical analysis of nonlinearities. Applied economics analysis, 27(79), 21-45. doi:10.1108/ AEA -06-2019-0005

Mester, L.J. (2017). Demographics and their implications for the economy and policy. Cato Institute's $35^{\text {th }}$ Annual Monetary conference; the future of monetary policy, Washington, DC.

Nagarajan, N.R., Teixeira, A.A and Silva, S.T. (2016). The impact of an aging population on economic growth; an exploratory review of the main mechanism. Analise social, 2018, Li(1), pp. 5-35.

Nuta, A.C. and Nuta, F.M. (2020). Modelling the influence of economic, demographic and institutional factors on Fiscal pressure using OLS, PCSE and FD-GMM approaches.

Odit, M.P., Dookhan, K. and Fauzel, S. (2010). The impact of education on economic growth; the case of Mauritius. International Business and Economics Research Journal, 9(8), 141-152.

Ogunjimi, J.A. and Oladipupo, D.O.(2018). Dynamics of demographics structure and economic growth in Nigeria. Munich Personal RePEc Archive (MPRA) paper no. 94988, accessed at https://mpra.ub.uni-muenchen.de/94988/

Oliinyk, O., Bilan, Y., Mishchuk, H., Akimov.O. and Vasa, L. (2021). The impact of migration of higher-skilled workers on the countries' competitiveness and economic growth, Montenegrin Journal of Economics, 17(3), 7-19. doi: 10.14254/1800$5845 / 2021.17-3-1$

Omoruyi, E. and Mitchel, M. (2021). Harnessing the Demographic dividend in Africa through Lessons from East Asia's Experience. Journal of Comparative Asian Development, 18(2), 1-38. doi: 10.4018/JCAD.20210701.oa1

Ozturk, I. (2001). The role of education in economic development; A theoretical perspective. Journal of Rural Development and Administration, 32(1), 39-47.

Pasichnyi, M. and Nepytaliuk, A. (2021). The contribution of demographic factors to economic growth. Problem of sustainable development, 1,(202), 219-229.

Pham, T.N. and Vo.D.H. (2019). Ageing Population and economic growth in developing countries a quantile regression approach. MPRA Paper no. 103279, accessed on $28^{\text {th }} /$ Agust, 2021

Preston,S.H. and Donoldson, P.(n.d). Population Growth and Economic Development; A discussion of Right Relationship that links demographic pattern and economic process. Asia-Pacific population Journal, 1(2), 3-66.

Rahman, N.H.A., Ismael, S. and Ridzuan, A.R.(2020). Aging population and economic growth; An empirical investigation. International Journal of academic research in Business and social sciences, 10(5), 609 -625.

Reynolds, A. (1992). What Is Competent Beginning Teaching? A Review of the Literature. Review of Educational Research, 62, 1-35. https://doi.org/10.3102/00346543062001001 
Ripley, B.D.(1996). Complements to Pattern Recognition and Neural Networks by Cambridge University Press.

Roka. D. (2020). Nexus of Economic Growth on Happiness and Inequality Re-examine the Paradox. Asian Journal of Economics, Business, and Accounting, 15(1) 35-49.

Schwarz G. (1978). Estimating the dimension of a model. The Annals of Statistics, 6(2), 461464.

Song, S.(2013). Demographic change and economic growth; empirical evidence from Asia. Honors projects. Paper no.121. retrieved at http:// digital commons. iwu. edu/ eco honproj /121 on 28th August 2021.

Stephan, K. and David, L. (2007). The impact of population growth on economic growth and poverty reduction in Uganda, Discussion paper No. 133, Gottingen University, Volkswirtschaftliches Seminar, Gottingen.

Stevenson, B. and Wolfers, J. (2008). Economic Growth and Subjective Well-Being Reassessing the Easterlin Paradox. Brookings Papers on Economic Activity, 1 1-87.

Stevenson, B. and Wolfers, J. (2013). Subjective Well-Being and Income: Is There AnyEvidence of Satiation? American Economic Review 103 (3), 598-604.

Sulaimon. M. O. (2015). Application of Weighted Least Squares Regression in Forecasting. International Journal of Recent Research in Interdisciplinary Sciences, 2(3), 45-54.

United Republic of Tanzania -URT. (2007). Information and Communication Technology (ICT) Policy for Basic Education-2007. Ministry of Education and Vocational Training. Dar Es Salaam, Tanzania.

United Republic of Tanzania -URT. (2014). The Education and Training Policy-2014. Ministry of Education and Vocational Training. Dar Es Salaam, Tanzania.

United Republic of Tanzania -URT. (2019c). Kagera Region Investment Guide. Presidential Office's Regional Administration and Local Government, Kagera, Tanzania.

United Republic of Tanzania-URT. (1999). The Public Services Retirement benefits Act1999. Dar Es Salaam, Tanzania.

United Republic of Tanzania-URT. (2003). The National Ageing Policy-2003.Ministry of Labour, Young Development and Sports. Dar Es Salaam, Tanzania.

United Republic of Tanzania-URT. (2008). The National Employment Policy -2008. Ministry of Labour and Young Development, Dar Es Salaam, Tanzania.

United Republic of Tanzania-URT. (2017). The National Health Policy -2017, sixth draft version. Ministry of Health, Community development, Gender, elderly and Children. Dar Es Salaam, Tanzania.

United Republic of Tanzania-URT. (2018). The Public Service social security Fund Act, 2018. Dar Es Salaam, Tanzania 
United Republic of Tanzania-URT.(2019a). National Accounts Statistics of Tanzania Mainland 2012-2018, $1^{\text {st }}$ Edition, in revised GDP series base 2015. National Bureau of Statistics, Ministry of Finance and Planning, Dodoma, Tanzania.

United Republic of Tanzania-URT.(2019b). National Accounts Statistics, popular Version 2018. National Bureau of Statistics, Dodoma, Tanzania.

Vlandas, T., McArthur, D. and Ganslmeier, M.(2021). Aging and the economy: A literature review of political and policy mechanism. Political research exchange, department of social policy and Intervention, University of Oxford.

Warner, B. and Misra, M. (2017). Understanding Neural Networks as Statistical Tools. The American Statistician, 50(4), 284-293.

Widarni,E.L. and Bawono, S.(2021). Human capital, technology, and economic growth. A case study of Indonesia. Journal of Asian Finance, Economics, and Business, 8(5), 0029-0035. doi: 10.13106-jafeb.2021.vol.8.no5.0029

Wijaya,A., Tasente, T., Darma, D.C. and Kasuma, J. (2021). Labour Force and Economic growth based on Demographic pressures, happiness, and Human Development; empirical from Romania. Journal of Eastern European and Central Asian Research, 8(1), 40-50. doi:org/10.15549/jeecar.v8i1.571

Yang, H. (2013).The Case for Being Automatic Introducing the Automatic Linear Modeling (LINEAR) Procedure in SPSS Statistics. Multiple Linear Regression Viewpoints, $39(2), 27-37$.

Yang, Y., Zheng, R. and Zhao, L.(2021). Population ageing, health investment, and economic growth: based on a cross-country paned data analysis. International Journal of Environmental Research and Public Health, 18, 1801, pp.1-16. doi. org/10.3390/ijerph18 041801

York Jr. E.T.(n.d). Education and economic growth. The University of Florida, pp. 31-40.

\section{Copyrights}

Copyright for this article is retained by the author(s), with first publication rights granted to the journal.

This is an open-access article distributed under the terms and conditions of the Creative Commons Attribution license (http://creativecommons.org/licenses/by/4.0/) 